\title{
Differential Modulation of Excitatory and Inhibitory Neurons during Periodic Stimulation
}

\author{
Mufti Mahmud ${ }^{1,2}$ and Stefano Vassanelli ${ }^{\text {* }}$ \\ ${ }^{1}$ NeuroChip Laboratory, Department of Biomedical Sciences, University of Padova, Padova, Italy, ${ }^{2}$ Institute of Information \\ Technology, Jahangirnagar University, Savar, Dhaka, Bangladesh
}

Non-invasive transcranial neuronal stimulation, in addition to deep brain stimulation, is seen as a promising therapeutic and diagnostic approach for an increasing number of neurological diseases such as epilepsy, cluster headaches, depression, specific type of blindness, and other central nervous system disfunctions. Improving its effectiveness and widening its range of use may strongly rely on development of proper stimulation protocols that are tailored to specific brain circuits and that are based on a deep knowledge of different neuron types response to stimulation. To this aim, we have performed a simulation study on the behavior of excitatory and inhibitory neurons subject to sinusoidal stimulation. Due to the intrinsic difference in membrane conductance properties of excitatory and inhibitory neurons, we show that their firing is differentially

OPEN ACCESS

Edited by:

Ignacio Obeso, Hospitales de Madrid and CEU-San Pablo University, Spain

Reviewed by:

Marcus Thomas Wilson, University of Waikato, New Zealand Mario Rosanova,

University of Milan, Italy

*Correspondence:

Stefano Vassanell stefano.vassanelli@unipd.it

Specialty section: This article was submitted to

Neurodegeneration,

a section of the journal

Frontiers in Neuroscience

Received: 24 November 2015 Accepted: 09 February 2016 Published: 25 February 2016

Citation:

Mahmud M and Vassanelli S (2016) Differential Modulation of Excitatory and Inhibitory Neurons during Periodic

Stimulation. Front. Neurosci. 10:62. doi: 10.3389/fnins.2016.00062 modulated by the wave parameters. We analyzed the behavior of the two neuronal types for a broad range of stimulus frequency and amplitude and demonstrated that, within a small-world network prototype, parameters tuning allow for a selective enhancement or suppression of the excitation/inhibition ratio.

Keywords: brain stimulation, transcranial stimulation, periodic stimulation, extracellular stimulation, excitatory and inhibitory neuron, neuronal network, Hodgkin-Huxley model, neurodegenerative diseases

\section{INTRODUCTION}

Non-invasive brain stimulation-i.e., transcranial magentic and current stimulation (Antal and Paulus, 2013; Davis and Koningsbruggen, 2013; Dayan et al., 2013; Paulus, 2014; Shin et al., 2015)_as well as invasive deep brain stimulation (DBS) (McConnell et al., 2012; Miocinovic et al., 2013; Green and Aziz, 2014; Coenen et al., 2015) deeply rely on electrically inducing changes of the neuronal transmembrane potential to modify excitability. Electrical stimulation of neurons has been adopted by many clinicians as means for treatment of a range of neurological disorders. For example, recent reports show its increasing use in Parkinson's disease (Krack et al., 2002; Alon et al., 2012; Obeso et al., 2013; Chou et al., 2015; de Hemptinne et al., 2015), epilepsy (Loddenkemper et al., 2001; Boex et al., 2007; Boon et al., 2009; Fisher et al., 2010; Nelson et al., 2011; Alarcón and Valentín, 2012; Berenyi et al., 2012; Orosz et al., 2014; Salanova et al., 2015), certain types of blindness (Rizzo et al., 2003; Freeman, 2010; Freeman et al., 2010; Antal et al., 2011; Gall et al., 2013), cluster headaches (Grover et al., 2009; Sillay et al., 2010; Matharu and Zrinzo, 2011; Piacentino et al., 2014; Hodaj et al., 2015), depression (Miller and Selman, 2009; Jorge and Robinson, 2011; Rizvi et al., 2011; Anderson et al., 2012; Henn, 2012; Cook et al., 2014; Concerto et al., 2015), obsessive-compulsive disorder (Nuttin et al., 2008; Jiménez-Ponce et al., 2009; Kohl et al., 2014; Grassi et al., 2015; Islam et al., 2015), and other movement disorders like essential tremor 
(Lozano, 2000; Volkmann and Benecke, 2002; Birdno et al., 2011; Gironell et al., 2014; Lettieri et al., 2015). However, the outcome of the method to many of these applications is reported to be limited due to lack of specificity of the stimulation (Fisher, 2011; Lozano and Lipsman, 2013; Shin et al., 2015). Thus, improvements are to be expected from protocols allowing for selective activation or inhibition of specific target neurons or classes of individual neurons, a strategy that can be broadly referred to as "differential stimulation" and that can be pursued by different approaches.

The "differential stimulation" of neurons can be approached both by means of invasive or non-invasive methods. For example, extracellular microstimulation has been used to selectively activate or inactivate neurons in ganglia using anodic or cathodic currents, respectively (Lu et al., 2008). By an alternative strategy, McIntyre and Grill reported that charge balanced asymmetric biphasic stimuli (McIntyre and Grill, 1999, 2000) can differentially activate neurons or fiber-of-passages by exploiting their difference in voltage thresholds and carefully tuning relevant stimulus parameters, e.g., amplitude, shape, frequency, and localization. They also reported on the effect of stimulus waveform and frequency on central nervous system (CNS) neurons through a detailed computer-based simulation of CNS cells and axons (McIntyre and Grill, 2002), where it was demonstrated that the relative position of the stimulating electrode plays an important role in activating a neuron. Results comparing experimental values and modeling prediction of threshold currents for varied electrode distances have also been reported (Joucla et al., 2012). Intriguingly, sinusoidal stimulation with microelectrodes has emerged as a possible tool to preferentially activate certain retinal cell types (e.g., photoreceptors, bipolar, and ganglion cells) (Freeman et al., 2010) or to induce complex phase-locked firing patterns of cortical pyramidal neurons (Brumberg and Gutkin, 2007).

How neurons are influenced by continuous or alternating electric fields depending on their position with respect to stimulating electrodes, morphology and electrical properties is matter of intense research also in the case of transcranial electrical stimulation approaches, such as the resurgent transcranial current stimulation (TCS) (Ali et al., 2013). For example, studies on transcranial direct current stimulation (tDCS) have shown that exposure to a uniform electric field promotes neuronal bursting and modulates spike timings (Radman et al., 2009). When alternating fields are considered, such as those produced by endogenous oscillations (Fröhlich and McCormick, 2010) and weak external fields (Deans et al., 2007) or by transcranial alterating current stimulation (tACS) (Herrmann et al., 2013; Reato et al., 2013), the general believe is that they can entrain brain oscillations. Furthermore, recent experimental evidence on tACS in humans supports the fascinating idea that excitation/inhibition balance (E/I) can be modulated by tuning the intensity of the stimulation current (Moliadze et al., 2012). The observation could be explained assuming that inhibitory neurons are more sensitive to alternating electrical stimulation and are already activated at low intensities, whereas excitatory neurons would require stronger stimulation. Recently, a similar capability on E/I modulation has been postulated also for tDCS (Krause et al., 2013).

As a matter of fact, understanding how excitatory and inhibitory neurons respond to extracellular electrical stimulation is still an open challenge. A particularly intriguing and clinically relevant aspect is their response to sinusoidal stimuli, such as those employed in tACS, and how it varies by tuning stimulus intensity and over the frequency range (Antal and Paulus, 2013).

This study reports simulation results of excitatory and inhibitory neurons' responses upon sinusoidal stimulation using varied frequencies and amplitudes. We focus on the effect of the extracellular field generated by the stimulus on action potentials firing. We found that it is possible, by careful selection of specific frequencies and amplitudes of the stimulus, to selectively enhance and inhibit either excitatory or inhibitory neurons. We show that the approach can be exploited to differentially modulate neuronal excitability within a network, suggesting its potential usefulness for non-invasive (e.g., tACS Kanai et al., 2008; Zaehle et al., 2010; Liew et al., 2014) as well as invasive brain stimulation (Coenen et al., 2015). Outside the tACS context, the concept can apply to neuroprosthetic devices (e.g., retinal stimulation using multicapacitor / multielectrode array, Eickenscheidt et al., 2012; Ghezzi, 2015; Lewis et al., 2015 and to brain-chip interfacing applications, Vassanelli et al., 2012; Vassanelli, 2014).

\section{METHODS}

Single compartment Hodgkin-Huxley (HH) neuron models (Hodgkin and Huxley, 1952) representing two main cortical neuron classes were implemented, the "regular spiking" (RS) excitatory neurons and the "fast spiking" (FS) interneurons (Connors and Gutnick, 1990). The HH model was chosen as it more faithfully describes membrane conductances dynamics with respect to, e.g., an Izhikevich model. This was of primary importance in our context were the neuronal response was investigated across a wide range of frequencies. In the implemented $\mathrm{HH}$ model all neurons had two main voltage-dependent ion channels, the $\mathrm{Na}^{+}$and the $\mathrm{K}^{+}$, whose conductances, in conjunction with an adjustable leak conductance, were sufficient to generate action potentials. Synaptic interactions were described by conductance-based synaptic currents that implement ionotropic glutamate receptors (AMPA and NMDA) and GABA receptors $\left(\mathrm{GABA}_{\mathrm{A}}\right)$ (Destexhe et al., 1994; Börgers et al., 2005). A small-world network of neurons was created by randomly connecting a predefined number of neighboring neurons assigned with a decided connection probability. The following subsections detail the models of the two classes of neurons, their synapses, and the network formation.

\subsection{Model Neuron}

Each neuron of both classes (RS and FS) was modeled using single compartment $\mathrm{HH}$ type model taken from the literature. There are many variants of kinetic models in the literature to govern the generation of action potentials (Herz et al., 2006) and we selected a model that describes the dynamics of membrane conductances and was previously adopted to match experimental 
findings (Fröhlich and McCormick, 2010). The constants and parameters used in the model to generate action potentials (see Table 1) were taken from the literature (for RS neuron: Traub et al., 1991 and Mainen et al., 1995; for FS neuron: Wang and

TABLE 1 | Constants and parameters for individual neuron classes with their units.

\begin{tabular}{lccl}
\hline Parameters & $\begin{array}{c}\text { Excitatory } \\
\text { neuron }\end{array}$ & $\begin{array}{c}\text { Inhibitory } \\
\text { neuron }\end{array}$ & Unit \\
\hline Membrane capacitance, $C_{m}$ & 1 & 1 & $\mu \mathrm{F} / \mathrm{cm}^{2}$ \\
Sodium reversal potential, $V_{N a}$ & 60 & 55 & $\mathrm{mV}$ \\
Potassium reversal potential, $V_{K}$ & -90 & -90 & $\mathrm{mV}$ \\
Leakage reversal potential, $V_{L}$ & -65 & -65 & $\mathrm{mV}$ \\
Max. sodium conductance, $\overline{g_{N a}}$ & 30 & 35 & $\mathrm{mS} / \mathrm{cm}^{2}$ \\
Max. potassium conductance, $\overline{g_{K}}$ & 100 & 9 & $\mathrm{mS} / \mathrm{cm}^{2}$ \\
Max. leakage conductance, $\overline{g_{L}}$ & 0.1 & 0.1 & $\mathrm{mS} / \mathrm{cm}^{2}$
\end{tabular}

Buzsáki, 1996). The membrane potential, $V$, was generated using Equation (1).

$$
C_{m} \frac{d V}{d t}=I_{N a}+I_{K}+I_{L}+I_{s y n}+I_{a p p}
$$

Here $I_{N a}, I_{K}, I_{L}, I_{s y n}$, and $I_{a p p}$ are the sodium, potassium, leakage, synaptic, and applied currents, respectively and were calculated using Equation (2). All differential equations were solved using second-order Runge-Kutta method (Press et al., 2007) with a step size $(d t)$ of $0.05 \mathrm{~ms}$.

$$
\begin{aligned}
I_{N a} & =\overline{g_{N a}} m^{3} h\left(V_{N a}-V\right) \\
I_{K} & =\overline{g_{K}} n^{4}\left(V_{K}-V\right) \\
I_{L} & =\overline{g_{L}}\left(V_{L}-V\right) \\
I_{s y n} & =I_{A M P A}+I_{N M D A}+I_{G A B A_{A}} \\
I_{a p p} & =C_{m} \frac{d V_{s}}{d t}
\end{aligned}
$$
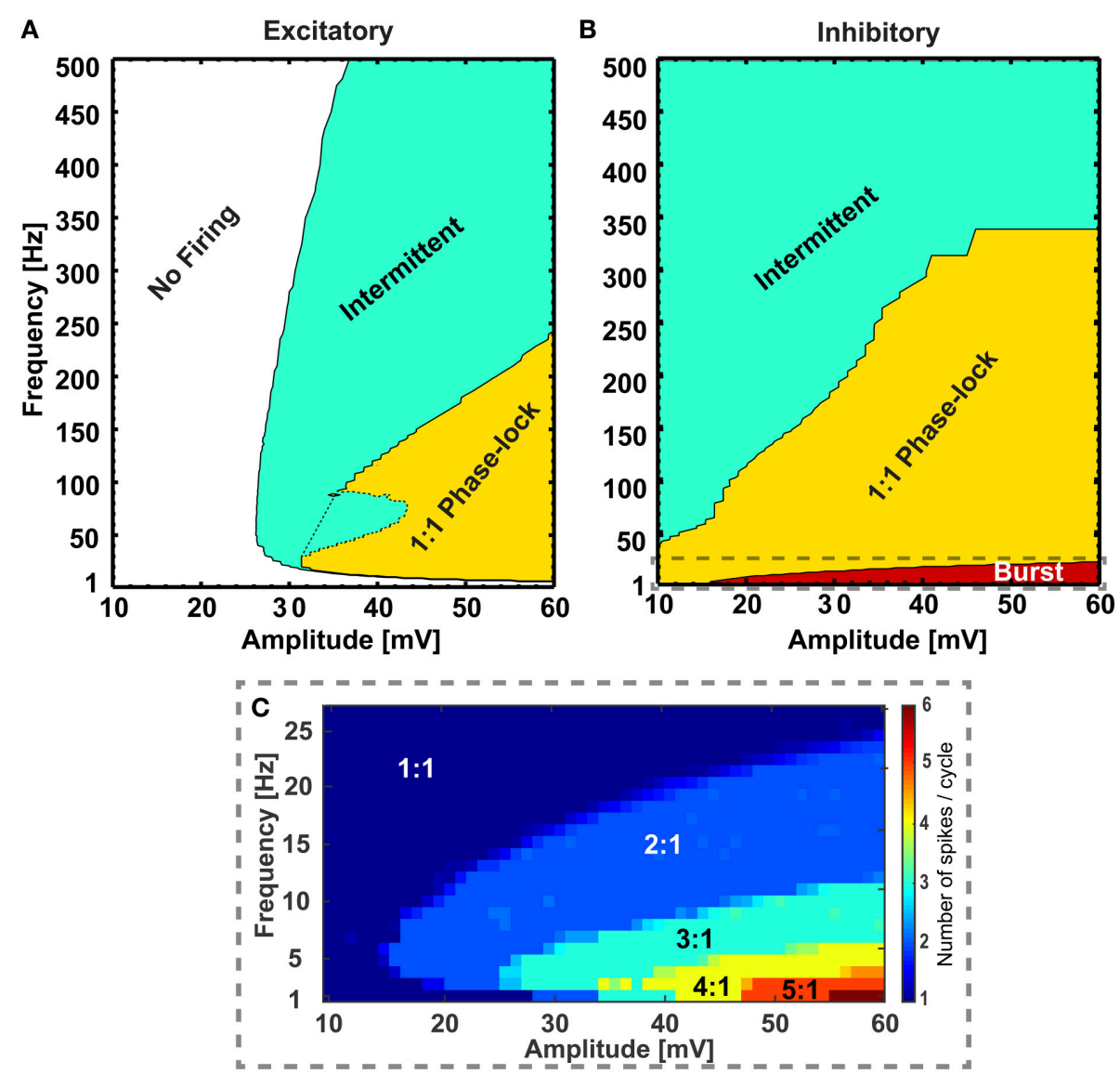

FIGURE 1 | Different firing regimes during sinusoidal stimulation. Excitatory (A) and inhibitory (B) neurons show different firing behaviors upon sinusoidal stimulation with different frequency and amplitude. The excitatory neurons do not respond to a range of amplitudes of sinusoidal stimulations (10- $26 \mathrm{mV}$, "No Firing" region) and at higher amplitudes (> $26 \mathrm{mV}$ ) with frequencies greater than $\sim 10 \mathrm{~Hz}$ they show phase lock ("1:1 Phase-lock" region) and intermittent ("Intermittent" region) firing behavior. Also, at a range of frequencies and amplitudes the excitatory neuron switches between "1:1 Phase-lock" and "Intermittent" firing [the dotted region in (A), referred as "Knee"]. On the other hand, the inhibitory neurons show bursting behavior in low frequencies ["Burst" region, zoomed in (C)], with gradual transition to phase-lock ("1:1 Phase-lock" region) and intermittent ("Intermittent" region) firing behavior with increasing amplitude and frequencies of the sinusoidal stimulations. In the burst region, the inhibitory neuron emits a varied number of action-potentials per cycle of stimulation (C) starting from $2: 1$ to $6: 1$ for the explored range of frequency and amplitude. 
The symbols $\overline{g_{N a}}, \overline{g_{K}}$, and $\overline{g_{L}}$ denote the maximum sodium, potassium, and leakage conductances respectively; $V_{\mathrm{Na}}, V_{K}$, and $V_{L}$ denote the reversal potentials of those channels; $m, h$, and $n$ denote the channel gating variables; $I_{A M P A}, I_{N M D A}$, and $I_{G A B A_{A}}$ denote the synaptic receptor mediated currents; and $C_{m}, V$, and $V_{s}$ represent membrane capacitance density, membrane voltage, and applied voltage (i.e., as generated by transcranial or intracranial stimulation), respectively. The parameters and units of the entities are listed in Table $\mathbf{1}$ and $V$ was calculated in $\mathrm{mV}$. For the sake of brevity units will be omitted in the rest of the text.

The channel gating variables, i.e., the activation and inactivation variables for the sodium current $(m$ and $h)$ and activation variable for the potassium current $(n)$ were calculated using Equation (3), where $x \in\{m, h, n\}$, and $\alpha_{x}$ and $\beta_{x}$ are the voltage dependent transition rates that govern the values taken by activation and inactivation variables.

$$
x_{\infty}(V)=\frac{\alpha_{x}(V)}{\alpha_{x}(V)+\beta_{x}(V)} \text { and } \frac{d x}{d t}=\alpha_{x}(1-x)-\beta_{x} x
$$

\subsubsection{Excitatory Neuron}

For the RS neuron, the gating variables were calculated using Equation (3) with $m_{\infty}, h_{\infty}$, and $n_{\infty}$ being the initial states of the sodium activation, sodium inactivation, and potassium activation variables, respectively. The voltage dependent transition rates for each of the $m, h$, and $n$ gating variables were updated using Equations $(4,5,6)$, respectively.

$$
\alpha_{m}(V)=\frac{0.182(V+35)}{1-\exp \left[\frac{-(V+35)}{9}\right]} \text { and } \beta_{m}(V)=\frac{-0.124(V-35)}{1-\exp \left[\frac{(V-35)}{9}\right]}
$$

$\alpha_{h}(V)=\frac{0.024(V+50)}{1-\exp \left[\frac{-(V+50)}{5}\right]}$ and $\beta_{h}(V)=\frac{-0.0091(V-75)}{1-\exp \left[\frac{(V-75)}{5}\right]}$

$$
\alpha_{n}(V)=\frac{0.2(V-20)}{1-\exp \left[\frac{-(V-20)}{9}\right]} \text { and } \beta_{n}(V)=\frac{-0.002(V-20)}{1-\exp \left[\frac{(V-20)}{9}\right]}
$$

\subsubsection{Inhibitory Neuron}

On the other hand, the voltage dependent transition rates for each of the $m, h$, and $n$ gating variables were calculated using Equations $(7,8,9)$, respectively. The initial states of these gating variables $\left(m_{\infty}, h_{\infty}\right.$, and $\left.n_{\infty}\right)$ were obtained similarly using Equation (3) with their own transition rates.

$$
\begin{aligned}
& \alpha_{m}(V)=\frac{-0.1(V+35)}{-1+\exp \left[\frac{-(V+35)}{10}\right]} \text { and } \\
& \beta_{m}(V)=4 \exp \left[\frac{-(V+60)}{18}\right]
\end{aligned}
$$

$$
\begin{aligned}
& \alpha_{h}(V)=0.07 \exp \left[\frac{-(V+58)}{20}\right] \text { and } \\
& \beta_{h}(V)=\frac{1}{1+\exp \left[\frac{-(V+28)}{10}\right]} \\
& \alpha_{n}(V)=\frac{-0.01(V+34)}{-1+\exp \left[\frac{-(V+34)}{10}\right]} \text { and } \\
& \beta_{n}(V)=0.125 \exp \left[\frac{-(V+44)}{80}\right]
\end{aligned}
$$

\subsection{Model Synapses}

Both GABAergic and glutamatergic synapses were designed to provide inhibition and excitation in the network. The inhibitory synapses were mediated by $\gamma$-aminobutyric acid $\left(\mathrm{GABA}_{\mathrm{A}}\right)$ receptors, whereas the excitatory synapses were mediated by a combination of $\alpha$-amino-3-hydroxy-5-methyl-4isoxazolepropionic acid (AMPA) and $\mathrm{N}$-methyl-D-aspartate (NMDA) receptors (Börgers et al., 2005).

The $\mathrm{GABA}_{\mathrm{A}}$ mediated synaptic currents were modeled by Equation (10) and summed up for the postsynaptically connecting $\mathrm{GABA}_{\mathrm{A}}$ mediated synapses.

$$
I_{G A B A_{A}}=\frac{g}{N_{I} \sum s_{i}(t)\left(V_{I}-V\right)}
$$

with

$$
g=\left\{\begin{array}{l}
g_{I E}, \text { if current neuron is excitatory, and } \\
g_{I I}, \text { if current neuron is inhibitory. }
\end{array}\right.
$$

Here $g$ is the strength of the synaptic coupling, $N_{I}$ is the number of presynaptic inhibitory neurons, $V_{I}$ is the resting potential of the inhibitory neuron (constant value of -70 was used), $V$ is the current neuron's membrane potential, and $s_{i}$ is the gating

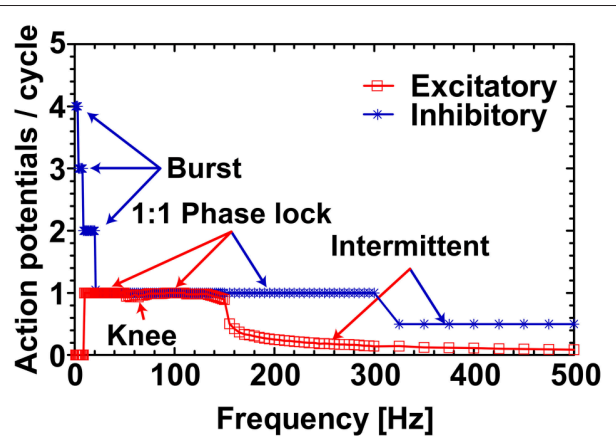

FIGURE 2 | Excitatory and inhibitory neurons response profile at $\mathbf{3 8} \mathbf{m V}$. The response profile of excitatory and inhibitory neurons as a function of number of spikes generated per cycle of sinusoidal stimulation at $38 \mathrm{mV}$. The applied frequency was from 1 to $500 \mathrm{~Hz}$ with a step of $1 \mathrm{~Hz}$ for $1-50 \mathrm{~Hz}, 2 \mathrm{~Hz}$ for $51-150 \mathrm{~Hz}, 5 \mathrm{~Hz}$ for $151-300 \mathrm{~Hz}$, and $25 \mathrm{~Hz}$ for $301-500 \mathrm{~Hz}$. The firing behavior outlined ("Burst," "1:1 Phase lock," and "Intermittent") are in complete agreement with the reference map shown in Figure 1. The "Knee" corresponds to the switching behavior (i.e., from 1:1 phase-lock to intermittent and back to 1:1 phase-lock) of the excitatory neuron in the frequency range $\sim 50-\sim 90 \mathrm{~Hz}$ as noticed in Figure 1. 
variable calculated using Equation (11). The $g_{I E}$ and $g_{I I}$ denote the synaptic coupling strength of inhibitory to excitatory and inhibitory to inhibitory synapses, respectively.

$$
\frac{d s}{d t}=\frac{1+\tanh \left(V_{p r e} / 10\right)}{2} \frac{1-s}{\tau_{R}}-\frac{s}{\tau_{D}}
$$

With $\tau_{R}$ being the rise time constant $(=0.5 \mathrm{~ms}), \tau_{D}$ being the decay time constant $(=10 \mathrm{~ms})$ and $V_{\text {pre }}$ being the membrane potential of the presynaptic neuron.

The AMPA and NMDA mediated synaptic currents were modeled by Equation (12) and summed up for the postsynaptically connecting AMPA and NMDA mediated synapses based on the synapse type under consideration.

$$
\begin{aligned}
I_{A M P A / N M D A} & =\frac{g}{N_{E} \sum s_{i}(t)\left(V_{E}-V\right)} \\
\text { with } & \\
g & = \begin{cases}g_{E E}, & \text { if current neuron is excitatory, and } \\
g_{E I}, & \text { if current neuron is inhibitory. }\end{cases}
\end{aligned}
$$

Here $N_{E}$ is the number of presynaptic excitatory neurons with either AMPA or NMDA type synapses, $V_{E}$ is the resting potential of the excitatory neuron (constant value of -70 was used), $V$ is the current neuron's membrane potential, and $s_{i}$ is the gating variable calculated using either Equation (11) (in case of AMPA mediated synapses) or Equation (13) (in case of NMDA mediated synapses). The $g_{E E}$ and $g_{E I}$ denote the synaptic coupling strength of excitatory to excitatory and excitatory to inhibitory synapses, respectively.

$$
\frac{d s}{d t}=\frac{1}{1+3.57 \exp \left(-0.062 V_{\text {post }}\right)} \frac{1+\tanh \left(V_{\text {pre }} / 10\right)}{2} \frac{1-s}{\tau_{R}}-\frac{s}{\tau_{D}}
$$

While calculating gating variables for the AMPA receptors, Equation (11) with $\tau_{R}=0.2 \mathrm{~ms}$ and $\tau_{D}=2 \mathrm{~ms}$ was used. On the other hand, the NMDA receptors' gating variables were calculated using Equation (13) with rise time constant $\tau_{R}=1 \mathrm{~ms}$, decay time constant $\tau_{D}=100$ $\mathrm{ms}$, and $V_{\text {post }}$ as the postsynaptic neuron's membrane potential.

\section{Excitatory}

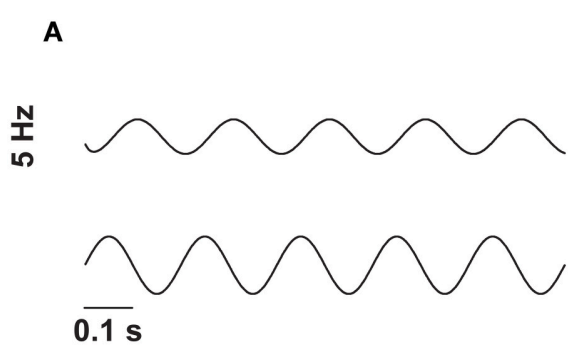

B
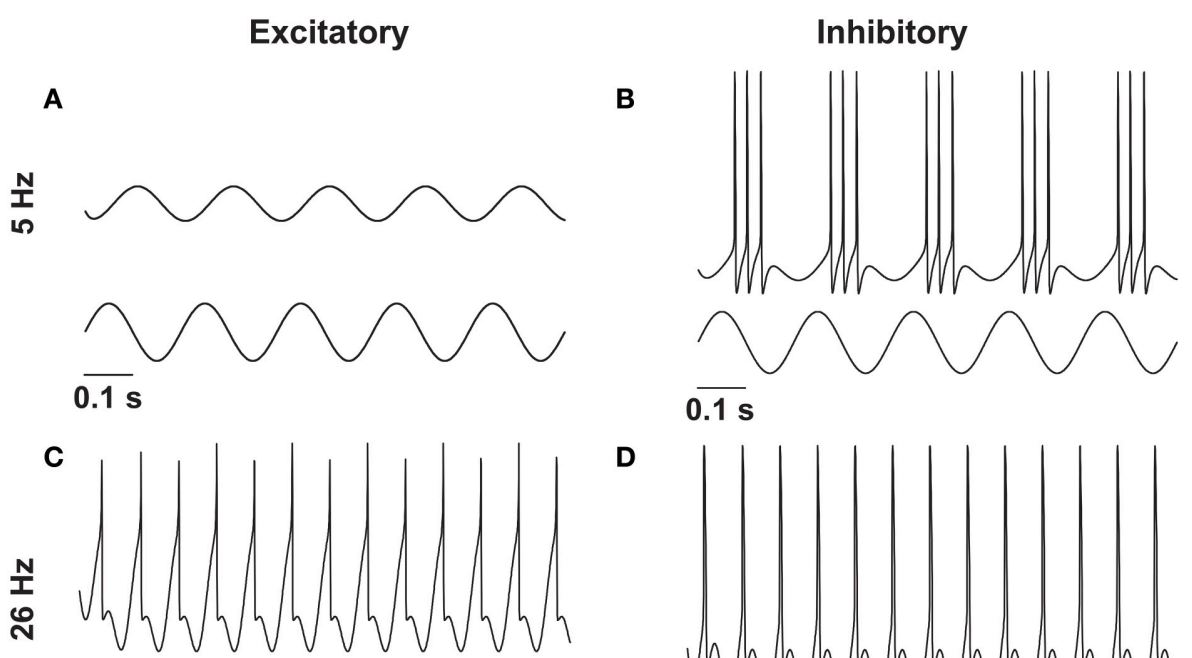

D

\section{$\overline{0.1 \mathrm{~s}}$}
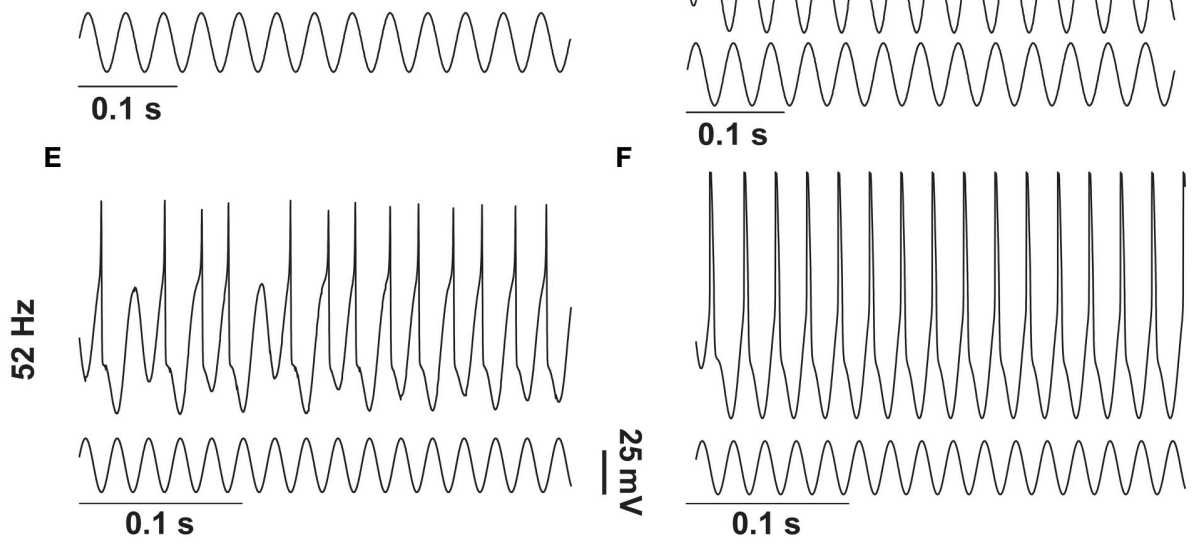

FIGURE 3 | Response of excitatory and inhibitory neurons to different frequencies of sinusoidal stimulations. Stimulating resting state excitatory and inhibitory neurons with different frequencies $(5 \mathrm{~Hz}, 26 \mathrm{~Hz}$, and $52 \mathrm{~Hz})$ of sinusoids of $38 \mathrm{mV}$ elicited different firing patterns as outlined in Figure 1. In case of the excitatory neuron $5 \mathrm{~Hz}$ stimulation was not enough to elicit action potentials (A), whereas the inhibitory neuron produced bursting activity (B). For $26 \mathrm{~Hz}$ action potentials were elicited in both types of neurons in a phase-locked fashion (C,D), and for $52 \mathrm{~Hz}$ the excitatory neuron moved to the intermittent region (E) and the inhibitory neuron still showed the phase-locked firing (F). 


\subsection{Model Small-World Network}

A small-world (SW) network topology was considered as a prototype model of brain neuronal network (Watts and Strogatz, 1998). As per the definition of SW topology, the network is generated from a ring lattice where each neuron is connecting to $K$ neighbors at random with a probability $p(0<p<1)$. Zero probability $(p=0)$ makes the network regular and maximum probability $(p=1)$ makes it a random network (Sun et al., 2011) (see Figure 4A).

The neuronal network consisted of RS excitatory neurons (E) and FS inhibitory neurons (I) at a ratio of $4: 1$. The $\mathbf{E}$ and $\mathbf{I}$ were synaptically connected using SW topology with $K=33$ neurons and $p=0.165$. Noteworthy, all the neurons of the SW network were subject to the same applied potential, as it can be reasonably assumed within a small volume of brain tissue that is exposed to an electric field. The choice of single compartment neurons is justified by the fact that the region of the axon hillock (considered to be isopotential with the soma) is by far the most sensitive to external electric stimulation with respect to action potential triggering (Nowak and Bullier, 1998).

The design of synapses are described in the Model Synapses subsection (See Section 2.2). We considered all possible synaptic connections in the network (i.e., $\mathbf{E} \rightarrow \mathbf{E}, \mathbf{E} \rightarrow \mathbf{I}, \mathbf{I} \rightarrow \mathbf{E}$, and $\mathbf{I} \rightarrow \mathbf{I}$ ) with predefined input strengths of arbitrary units $(\mathbf{E} \rightarrow \mathbf{E}: 0.1$, $\mathbf{E} \rightarrow \mathbf{I}: 0.1, \mathbf{I} \rightarrow \mathbf{E}: 0.05$, and $\mathbf{I} \rightarrow \mathbf{I}: 0.06)$ to create the connectivity weight matrices without recurrent connectivity. We further used a scaling factor for the excitatory and inhibitory synapses with values 0.03 and 0.06 , respectively.

\subsection{Model Background Network}

The SW network with RS and FS neurons (see Section 2.3) remained at rest without external input. To simulate

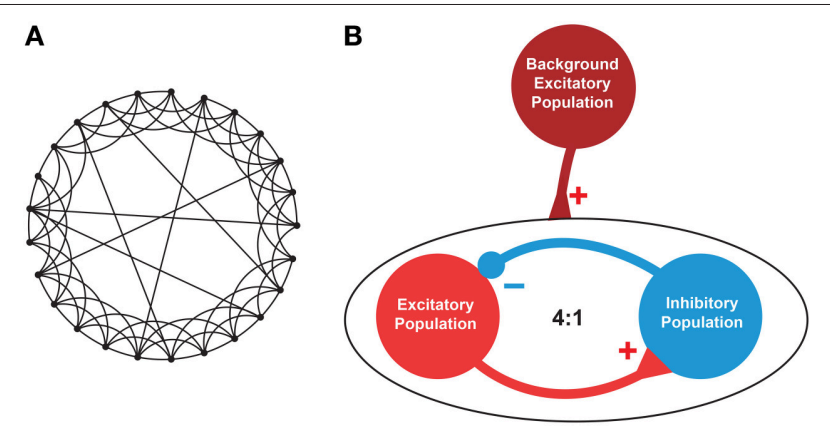

FIGURE 4 | Architecture of the neuronal network. (A). An instance of a representative small-world network with 25 nodes out of which $6(K)$ nodes were linked via random rewiring with probability $p=0.24$. (B). A network consisting of excitatory $(\mathbf{E})$ and inhibitory $(\mathbf{I})$ neurons at $4: 1$ ratio was created with $\mathbf{E} \rightarrow \mathbf{E}, \mathbf{E} \rightarrow \mathbf{I}, \mathbf{I} \rightarrow \mathbf{E}$, and $\mathbf{I} \rightarrow \mathbf{I}$ synaptic connectivity. To mimic the background activity or driving force, another population of excitatory neurons was used (maroon circle). This background population provided excitatory inputs to $50 \%$ of the excitatory (red circle) and inhibitory (blue circle) neurons to maintain a stable firing pattern. The excitatory-inhibitory population consisted of total $N(=200, E=160, I=40)$ neurons, each randomly connected to other $K(=33)$ neurons with $p(=0.165)$ connection probability using undirected edges creating a small-world network as described in Watts and Strogatz (1998). a background noise input and drive the SW network to spontaneous activity, we used an external neuronal population not exposed to electric stimulation (called "background population," see Figure 4B) consisting of 30 Izhikevich neurons (see Equations 14, 15) (Izhikevich, 2003) randomly connecting to $50 \%$ neurons in the target population through AMPA mediated synapses (see Equations 12, 11). In this case, Izhikevich neurons were preferred to $\mathrm{HH}$ neurons because computationally favorable and considering that they solely represented a source of spikes.

$$
\begin{aligned}
& \frac{d v}{d t}=0.04 v^{2}+5 v+140-u+I \\
& \frac{d u}{d t}=a(b v-u)
\end{aligned}
$$

with an after-spike resetting function defined by Equation (15).

$$
\text { if } v \geq 30 \mathrm{mV} \text {, then }\left\{\begin{array}{l}
v \leftarrow c \\
u \leftarrow u+d
\end{array}\right.
$$

Here, $v, u, t$, and $I$ are membrane potential, membrane recovery variable representing the $\mathrm{Na}^{+}$and $\mathrm{K}^{+}$channel kinetics, time, and injected current respectively. $a$ is the time scale of $u, b$ is the sensitivity of $u, c$ is the after-spike resetting value of $v$, and $d$ is the after-spike resetting value of $u$. The values used for $a, b, c$, and $d$ are $0.1,0.2,-65$, and 2 respectively. The values of $v$ and $c$ are expressed in $\mathrm{mV}$, and $t$ in $\mathrm{ms}$.

Each of the neurons in the background population constantly received a zero-mean Gaussian noise ( $I$ in Equations 14 ) with a variance of 4.6 that generated enough AMPA mediated excitation

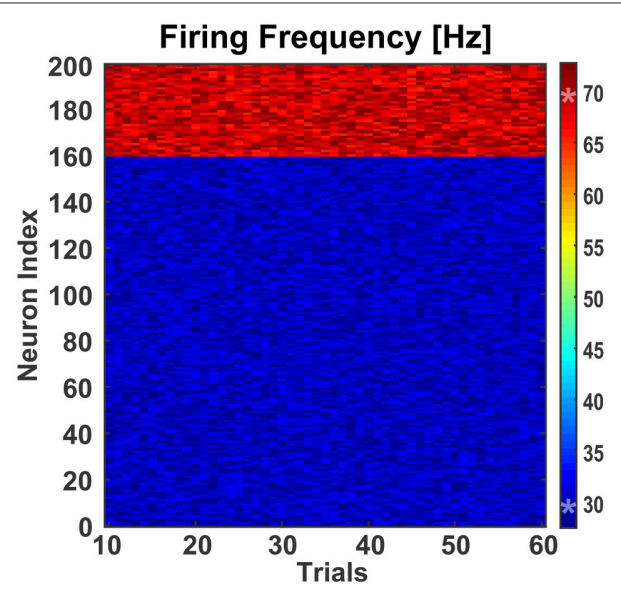

FIGURE 5 | Effect of background activity on network. To test the effect of differential modulation of excitatory and inhibitory neurons, the small-world network was fed with excitatory synaptic inputs from a background population consisting of 30 Izhikevich neurons. These neurons were stimulated with a randomly generated zero-mean Gaussian noise of variance 4.6. This generated enough excitatory synaptic conductance to activate the target population of excitatory and inhibitory neurons. Over 60 trials, the mean firing frequencies of the excitatory and inhibitory neurons were $30.00 \mathrm{~Hz}( \pm 0.11 \mathrm{~Hz})$ and $68.98 \mathrm{~Hz}( \pm 0.27 \mathrm{~Hz}$ ), respectively. The two asterisks ('*') on the colorbar represent the mean firing frequencies. 
to activate the target population which then maintained a steady firing pattern.

\section{RESULTS AND DISCUSSION}

We first examined how the individual RS excitatory and FS inhibitory neurons respond to sinusoidal modulation of their transmembrane potential, e.g., as a result of extracellular stimulation with alternating current. We assessed different frequencies and strengths and created maps of firing patterns for the two types of neurons (see Figure 1). Maps show how the amplitude-frequency relationship affects the neuronal firing. Four possible modes were found: (i) non-firing, (ii) phase-lock firing with one action potential per peak (i.e., following a 1:1 relation), (iii) an intermediate condition where peaks of the sinusoidal modulation were not all associated to an action potential (i.e., intermittent firing in Figure 1) and (iv) bursting (i.e., with multiple action potentials per peak). Interestingly, excitatory neurons displayed the first three modes of response (Figure 1A): the no firing mode in the very low frequency range and for low stimulation amplitudes, the phase-locked behavior in the intermediate frequency range and for high amplitudes, and the intermittent firing in between. Conversely, inhibitory neurons were characterized by either bursting (Figure 1C), phase-locked or intermittent behavior when moving from the low to the high frequency range (Figure 1B).

\subsection{Differential Modulation of Single Neurons}

Due to intrinsic differences in the membrane properties between the two classes of neurons, they exhibit variation in their firing

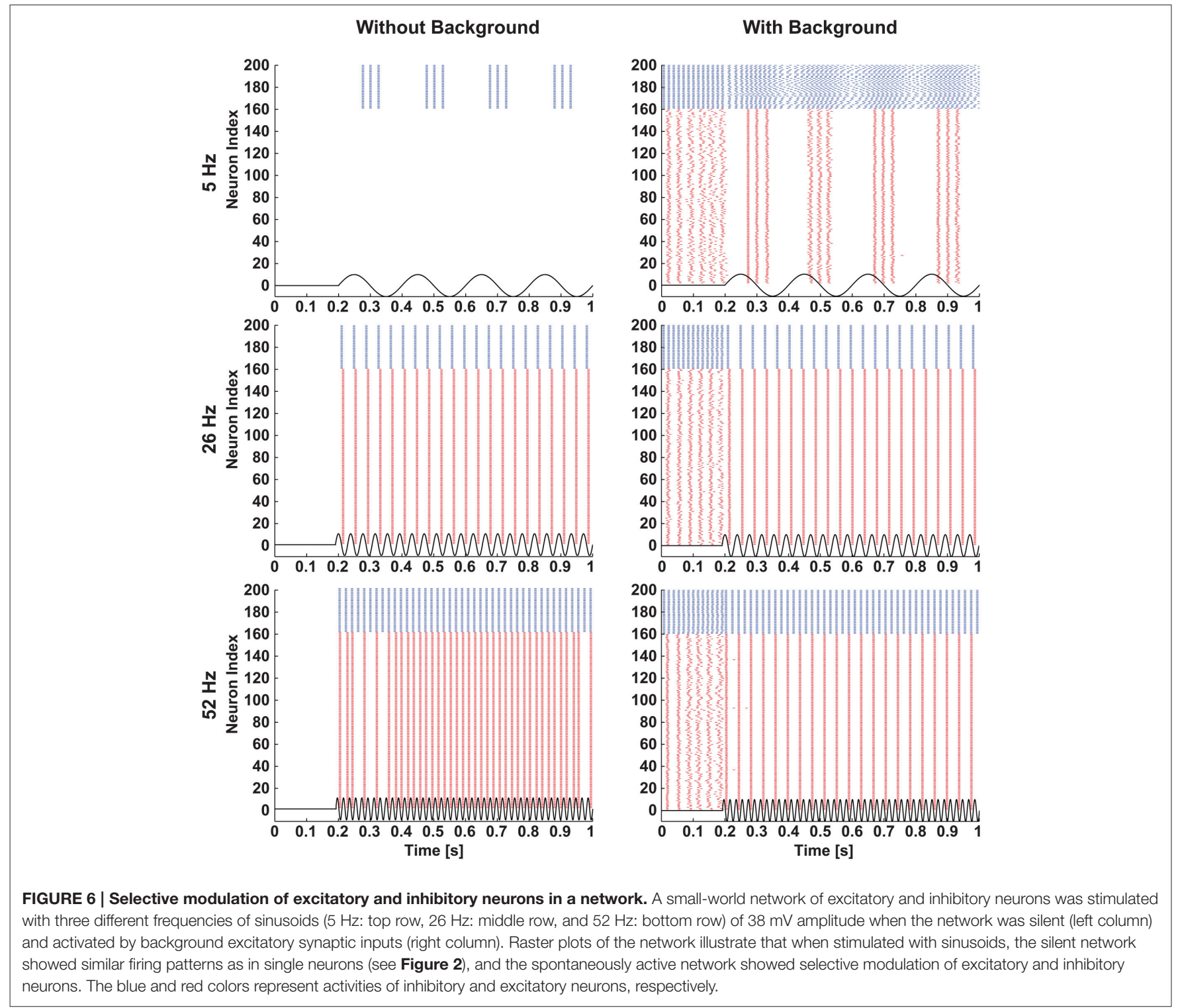


patterns while subject to the same periodic modulation as seen in Figure 1. After simulating the firing behavior of neurons from both classes for a large range of stimulating sinusoidal waveforms (frequency range: 1 to $500 \mathrm{~Hz}$, and amplitude range: 10 to $60 \mathrm{mV}$ ), invariant to background perturbations (i.e., with or without sub-threshold background inputs to the single neurons), the RS neurons remained silent for a range of amplitudes and frequencies of the input signals $(10 \leq$ amplitude $\leq 26 \mathrm{mV}, 1 \leq$ frequency $\leq 10 \mathrm{~Hz}$ ), but in the same range the FS neurons exhibited firing patterns that varied from bursting to 1:1 phase lock to intermittent, depending on input signal's amplitude and frequency. Furthermore, though the RS neurons responded to input signals with amplitude $>26$ $\mathrm{mV}$ and frequency $>10 \mathrm{~Hz}$ by firing action potentials, the firing pattern was irregular for the range (26 $\leq$ amplitude $\leq$ $44 \mathrm{mV}, 10 \leq$ frequency $\leq 80 \mathrm{~Hz}$ ), that is the pattern was
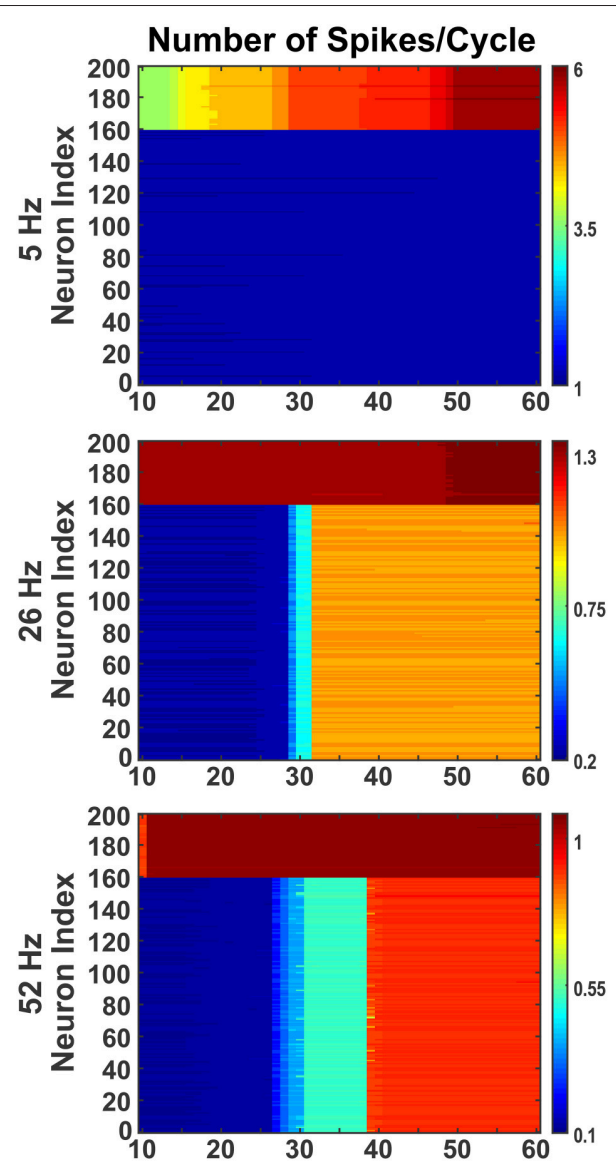

Stimulation Amplitude [mV]

FIGURE 7 | Effect of stimulation amplitude on active network. The network was stimulated with varied amplitude of sinusoids (10 mV to $60 \mathrm{mV}$ with step of 1) at three different frequencies $(5 \mathrm{~Hz}, 26 \mathrm{~Hz}$, and $52 \mathrm{~Hz})$, as in Figure 6, when the network was activated by synaptic inputs from the background population. Even during the presence of background activity, stimulating the network with different amplitudes of sinusoids, the individual neurons' firing behavior was comparable to the ones noticed at $38 \mathrm{mV}$. The Y-axis shows the neurons index where 1 to 160 are excitatory and 161 to 200 are inhibitory. The colorbar shows the number of spikes per cycle. switching between intermittent and 1:1 phase lock depending on specific amplitude-frequency combinations (dotted area in Figure 1A). On the contrary, in this range of stimulation, the FS neurons show steady progression in firing patterns (i.e., either "1:1 phase lock to intermittent" or "burst to 1:1 phase lock to intermittent") with increasing stimulus strength and frequency.

To exemplify the firing behavior mapped in Figure 1, individual neuronal classes were stimulated at $38 \mathrm{mV}$ for the whole frequency range $(1-500 \mathrm{~Hz})$. As expected, when the number of elicited action potentials per sinusoidal cycle was plotted against the applied frequencies, the individual neuronal classes showed different firing patterns within given frequency ranges Figure 2. The inhibitory neuron (blue circled line) showed bursting behavior (with 4:1,3:1, and 2:1 action potentials per cycle ratio) for input signals up to $20 \mathrm{~Hz}$ and the excitatory neuron (red squared line) remained silent for the first 10 $\mathrm{Hz}$. However, during the subsequent range of intermediate frequencies $(20-\sim 300 \mathrm{~Hz}$ ), while the inhibitory neuron fired 1:1 phase-locked action potentials, the excitatory neuron first fired in a 1:1 phase-locked mode $(10-\sim 110 \mathrm{~Hz})$ with a short knee-shaped interval to an intermittent state $(\sim 50-\sim 90 \mathrm{~Hz})$, and then stably reverted to an intermittent regime. In fact, for the frequencies above $300 \mathrm{~Hz}$ both the neuronal classes showed intermittent firing in agreement with the reference maps.

To clearly visualize the differential responses of the two neuronal types to sinusoidal stimulation, we selected three representative frequencies of sinusoidal input signals $(5,26$, and $52 \mathrm{~Hz}$ ) from Figure 2. As seen in Figure 3, at $5 \mathrm{~Hz}$, the inhibitory neuron fires bursts of action potentials (Figure 3B) but the excitatory neuron remains silent (Figure 3A); at $26 \mathrm{~Hz}$, both types of neurons fire action potentials 1:1 phase locked to the stimulation signals (Figure 3C,D); and at $52 \mathrm{~Hz}$, the excitatory neuron exhibits intermittent firing (Figure 3E) while the inhibitory neuron still fires in phase to the input signal (Figure 3F).

\subsection{Differential Modulation of Neuronal Network}

We further investigated the effect of differential sinusoidal stimulation on neurons forming a neuronal network with SW topology (Figure 4A), a condition more closely resembling real brain circuits with respect to isolated neurons (Bullmore and Sporns, 2012). We assessed two distinct network conditions: (i) when the SW network was silent, i.e., without any external supply except the test inputs; and (ii) when the SW network was driven to be spontaneously active.

The latter condition was achieved by adding an external "background" neuronal population driving the SW network to a basal activity regime (Figure 4B). The background neuronal population was activated by perturbing it with zero-mean Gaussian noise, which caused spikes uniformly distributed in the population. 50\% neurons from both classes in the SW network received AMPA mediated excitatory synaptic inputs from the background population which were enough to drive the SW 


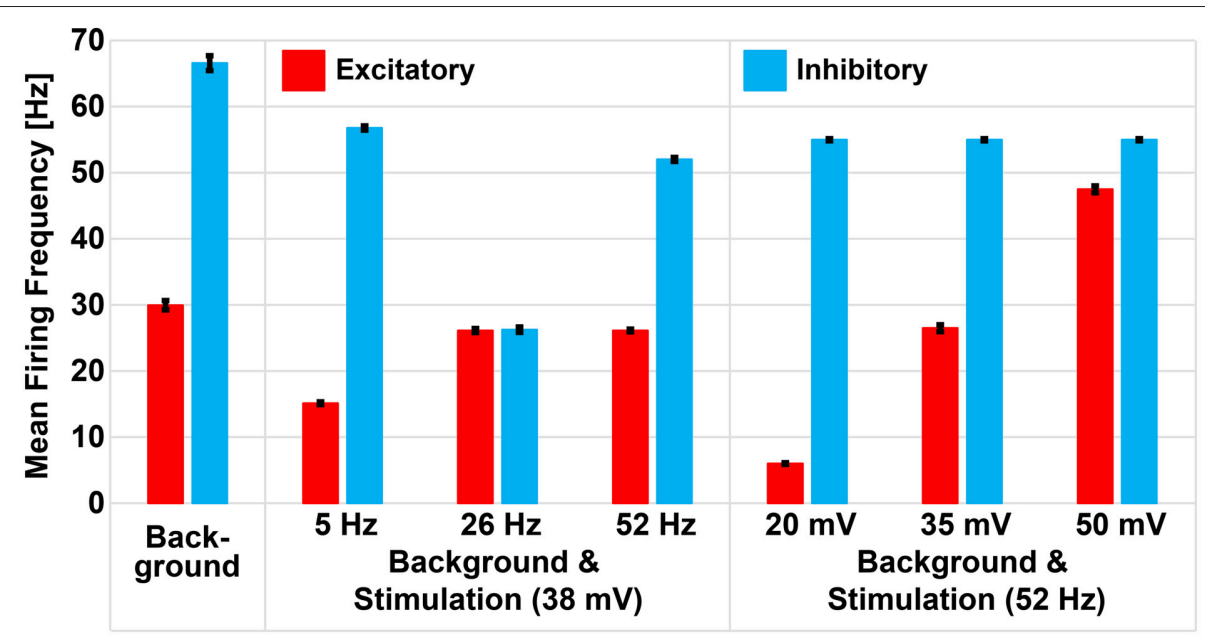

FIGURE 8 | Repetitive stimulation changes mean firing rate of excitatory and inhibitory neurons in presence of background activity . Excitatory and inhibitory neurons of the small-world network had mean firing frequencies of $29.94 \mathrm{~Hz}( \pm 0.7 \mathrm{~Hz})$ and $66.56 \mathrm{~Hz}( \pm 1.12 \mathrm{~Hz})$, respectively, as a result of excitation received from the excitatory background population. Sinusoidal stimulation at $38 \mathrm{mV}$ selectively modulated the mean firing rate of excitatory and inhibitory neurons to $15.12 \mathrm{~Hz}( \pm 0.2 \mathrm{~Hz})$ and $56.75 \mathrm{~Hz}( \pm 0.32 \mathrm{~Hz})$ during $5 \mathrm{~Hz}, 26.12 \mathrm{~Hz}( \pm 0.1 \mathrm{~Hz})$ and $26.24 \mathrm{~Hz}( \pm 0.1 \mathrm{~Hz})$ during $26 \mathrm{~Hz}$, and $26.12 \mathrm{~Hz}( \pm 0.14 \mathrm{~Hz})$ and $51.99 \mathrm{~Hz}( \pm 0.1$ $\mathrm{Hz}$ ) during $52 \mathrm{~Hz}$ stimulation. However, fixing the stimulation frequency at $52 \mathrm{~Hz}$ and varying the amplitudes, we noticed gradual enhancement of excitatory neuron only (i.e., from $6.02 \pm 0.12 \mathrm{~Hz}$ to $26.47 \pm 0.51 \mathrm{~Hz}$ to $47.47 \pm 0.52 \mathrm{~Hz}$ ) while the inhibitory neuron remained unchanged (54.97 $\pm 0.16 \mathrm{~Hz}$ ).

network (see Figure 5) and generate excitatory and inhibitory synaptic conductances comparable to those of a real biological network (Guillamon et al., 2006).

In both network conditions (i.e., silent and spontaneously active) the individual neurons belonging to different classes were differentially modulated (see Figures 6, 7). In the spontaneously active network, differential modulation was forcing the spontaneously active SW network to a highly synchronized state (Figure 6, right column). This phenomenon can be attributed to the modulation of synaptic coupling in the SW network (Breakspear et al., 2003), and selective amplification of cortical cells' responses at preferred frequencies by intra-network inputs from similarly tuned neurons (Liu et al., 2007; Rotstein and Nadim, 2014). Conversely, in the case of the silent network condition, the modulation (Figure 6, left column) closely matched the single-neuron reference map (see Figure 1).

Moreover, in response to sinusoidal stimulation with given amplitudes and frequencies, the neurons exhibit either an increase or a decrease in their spiking rates with respect to background activity. The inhibitory neurons in the network were found to be more susceptible to sinusoids at lower intensities, matching qualitatively previous experimental observations (Moliadze et al., 2012), and frequencies (Reato et al., 2013). As seen in Figure 7, at low frequency (i.e., 5 $\mathrm{Hz}$ ) with increasing intensity, the inhibitory neurons show frequent change in action potential firing rate (indicated by color stripes in figure) compared to excitatory neurons which fire steadily (indicated by uniform color in figure). The reverse happens at higher frequencies (i.e., 26 and $52 \mathrm{~Hz}$ ), where the excitatory neurons show an increasing enhancement of firing rates (indicated by color stripes in figure), while the inhibitory ones fire invariably (indicated by uniform color in figure). This differential activation of excitatory and inhibitory neurons gives rise to a change of the excitation/inhibition ratio (E/I) in the network which is dependent form the amplitude and frequency of the stimulus, and that may represent a mechanism behind experimental and clinical observations during tACS (Antal and Paulus, 2013; Herrmann et al., 2013).

Dysregulation of $\mathrm{E} / \mathrm{I}$ has been associated to many CNS disorders (Eichler and Meier, 2008), characterized by inefficient information exchange in brain regions. This inefficacy could be caused by loss of homeostatic control of excitation and inhibition (Krause et al., 2013), making it crucial to find therapeutic approaches to restore physiological E/I. To this aim, also on the basis of our results, the E/I may be modulated by finely tuning the amplitude and frequency of sinusoidal stimulation. The concept is evidenced in Figure 8 were we show how, by changing stimulation parameters, the average activity of excitatory and inhibitory neurons in a spontaneoulsy active network can be tuned modulating, in turn, the E/I.

\section{CONCLUSION}

We provide evidence that, leveraging the different properties of voltage-dependent membrane conductances in excitatory and inhibitory neurons, sinusoidal stimuli can be used to differentially modulate their firing. In particular, basing on simulations of a network of excitatory and inhibitory neurons exposed to a sinusoidal modulation of the extracellular potential, we showed that sinusoidal stimulation could modulate the E/I. In practice, all electrical stimulation methods adopted in the experimental and clinical context and causing sinusoidal voltage changes in the extracellular fluid of the brain tissue could be 
suitable for the purpose. These include implanted electrodes, such as in DBS, and transcranial non-invasive stimulation approaches such as tACS. However, further elaboration will be necessary to assess the real potential of the approach in clinics. First of all, an unknown contribution will exist from fibers stimulation by the electric field (Roth and Basser, 1990; Herrmann et al., 2013). Second, synaptic plasticity phenomena may also influence network dynamics upon sinusoidal stimulation, as proposed by Antal and Paulus (2013); Zaehle et al. (2010). Finally, it will be crucial to precisely estimate the transmembrane potential in neurons during tACS, taking into account the impedence of the neuronal membrane and its shunting influence at higher frequencies. In fact, despite technical advances to strengthen stimulation (Herrmann et al., 2013), the transmembrane potential modulation caused by tACS may turn out to be too weak to control E/I for clinical usage. Despite these unknowns, and in future perspective, differential sinusoidal stimulation may prove to be a versatile approach in clinics to restore physiological balance between excitation and inhibition in a number of neurological disorders.

\section{REFERENCES}

Alarcón, G., and Valentín, A. (2012). Cortical stimulation with single electrical pulses in human epilepsy. Clin. Neurophysiol. 123, 223-224. doi: 10.1016/j.clinph.2011.07.001

Ali, M. M., Sellers, K. K., and Fröhlich, F. (2013). Transcranial alternating current stimulation modulates large-scale cortical network activity by network resonance. J. Neurosci. 33, 11262-11275. doi: 10.1523/JNEUROSCI.586712.2013

Alon, G., Yungher, D. A., Shulman, L. M., and Rogers, M. W. (2012). Safety and immediate effect of noninvasive transcranial pulsed current stimulation on gait and balance in parkinson disease. Neurorehabil. Neural Repair. 26, 1089-1095. doi: $10.1177 / 1545968312448233$

Anderson, R. J., Frye, M. A., Abulseoud, O. A., Lee, K. H., McGillivray, J. A., Berk, M., et al. (2012). Deep brain stimulation for treatment-resistant depression: efficacy, safety and mechanisms of action. Neurosci. Biobehav. Rev. 36, 19201933. doi: 10.1016/j.neubiorev.2012.06.001

Antal, A., and Paulus, W. (2013). Transcranial alternating current stimulation (tacs). Front. Hum. Neurosci. 7:317. doi: 10.3389/fnhum.2013.00317

Antal, A., Paulus, W., and Nitsche, M. A. (2011). Electrical stimulation and visual network plasticity. Restor. Neurol. Neurosci. 29, 365-374. doi: 10.3233/rnn2011-0609

Berényi, A., Belluscio, M., Mao, D., and Buzsaki, G. (2012). Closed-loop control of epilepsy by transcranial electrical stimulation. Science 337, 735-737. doi: $10.1126 /$ science. 1223154

Birdno, M. J., Kuncel, A. M., Dorval, A. D., Turner, D. A., Gross, R. E., and Grill, W. M. (2011). Stimulus features underlying reduced tremor suppression with temporally patterned deep brain stimulation. J. Neurophysiol. 107, 364-383. doi: $10.1152 /$ jn. 00906.2010

Boëx, C., Vulliémoz, S., Spinelli, L., Pollo, C., and Seeck, M. (2007). High and low frequency electrical stimulation in non-lesional temporal lobe epilepsy. Seizure 16, 664-669. doi: 10.1016/j.seizure.2007.05.009

Boon, P., Raedt, R., Herdt, V., Wyckhuys, T., and Vonck, K. (2009). Electrical stimulation for the treatment of epilepsy. Neurotherapeutics 6, 218-227. doi: 10.1016/j.nurt.2008.12.003

Börgers, C., Epstein, S., and Kopell, N. J. (2005). Background gamma rhythmicity and attention in cortical local circuits: a computational study. Proc. Natl. Acad. Sci. U.S.A. 102, 7002-7007. doi: 10.1073/pnas.05023 66102

\section{AUTHOR CONTRIBUTIONS}

SV conceived the basic idea of differential sinusoidal stimulation; MM developed the model and wrote the code to assess the differential sinusoidal stimulation concept. MM and SV wrote the manuscript. Both authors have contributed to, seen and approved the final manuscript.

\section{FUNDING}

Financial support from the 7th Framework Programme of the European Commission through "CyberRat" (http:// www.vassanellilab.eu/projects/cyberrat/, GA no. 216528) and "RAMP" projects (www.rampproject.eu, GA no. 612058) are acknowledged.

\section{ACKNOWLEDGMENTS}

The authors are particularly thankful to Dr. M. Mostafizur Rahman and Mr. Giacomo Bassetto for their help and fruitful discussion.

Breakspear, M., Terry, J. R., and Friston, K. J. (2003). Modulation of excitatory synaptic coupling facilitates synchronization and complex dynamics in a biophysical model of neuronal dynamics. Network 14, 703-732. doi: 10.1088/0954-898X_14_4_305

Brumberg, J. C., and Gutkin, B. S. (2007). Cortical pyramidal cells as non-linear oscillators: experiment and spike-generation theory. Brain Res. 1171, 122-137. doi: 10.1016/j.brainres.2007.07.028

Bullmore, E., and Sporns, O. (2012). The economy of brain network organization. Nat. Rev. Neurosci. 13, 336-349. doi: 10.1038/nrn3214

Chou, Y., Hickey, P. T., Sundman, M., Song, A. W., and Chen, N. (2015). Effects of repetitive transcranial magnetic stimulation on motor symptoms in parkinson disease: a systematic review and meta-analysis. JAMA Neurol. 72, 432-440. doi: 10.1001/jamaneurol.2014.4380

Coenen, V. A., Amtage, F., Volkmann, J., and Schläpfer, T. E. (2015). Deep brain stimulation in neurological and psychiatric disorders. Dtsch. Arztebl. Int. 112, 519-526. doi: 10.3238/arztebl.2015.0519

Concerto, C., Lanza, G., Cantone, M., Ferri, R., Pennisi, G., Bella, R., et al. (2015). Repetitive transcranial magnetic stimulation in patients with drug-resistant major depression: a six-month clinical follow-up study. Int. J. Psychiatry Clin. Pract. 19, 252-258. doi: 10.3109/13651501.2015.1084329

Connors, B. W., and Gutnick, M. J. (1990). Intrinsic firing patterns of diverse neocortical neurons. Trends Neurosci. 13, 99-104. doi: 10.1016/01662236(90)90185-D

Cook, I. A., Espinoza, R., and Leuchter, A. F. (2014). Neuromodulation for depression: invasive and noninvasive (deep brain stimulation, transcranial magnetic stimulation, trigeminal nerve stimulation). Neurosurg. Clin. N. Am. 25, 103-116. doi: 10.1016/j.nec.2013.10.002

Davis, N. J., and Koningsbruggen, M. V. (2013). 'Non-invasive' brain stimulation is not non-invasive. Front. Syst. Neurosci. 7:76. doi: 10.3389/fnsys.2013.00076

Dayan, E., Censor, N., Buch, E. R., Sandrini, M., and Cohen, L. G. (2013). Noninvasive brain stimulation: from physiology to network dynamics and back. Nat. Neurosci. 16, 838-844. doi: 10.1038/nn.3422

de Hemptinne, C., Swann, N. C., Ostrem, J. L., Ryapolova-Webb, E. S., San Luciano, M., Galifianakis, N. B., et al. (2015). Therapeutic deep brain stimulation reduces cortical phase-amplitude coupling in Parkinson's disease. Nat. Neurosci. 18, 779-786. doi: 10.1038/nn.3997

Deans, J. K., Powell, A. D., and Jefferys, J. G. R. (2007). Sensitivity of coherent oscillations in rat hippocampus to AC electric fields. J. Physiol. 583, 555-565. doi: 10.1113/jphysiol.2007.137711 
Destexhe, A., Mainen, Z. F., and Sejnowski, T. J. (1994). An efficient method for computing synaptic conductances based on a kinetic model of receptor binding. Neural Comput. 6, 14-18. doi: 10.1162/neco.1994. 6.1 .14

Eichler, S. A., and Meier, J. C. (2008). E-i balance and human diseases from molecules to networking. Front. Mol. Neurosci. 1, 2. doi: 10.3389/neuro.02.002.2008

Eickenscheidt, M., Jenkner, M., Thewes, R., Fromherz, P., and Zeck, G. (2012). Electrical stimulation of retinal neurons in epiretinal and subretinal configuration using a multicapacitor array. J. Neurophysiol. 107, 2742-2755. doi: 10.1152/jn.00909.2011

Fisher, R., Salanova, V., Witt, T., Worth, R., Henry, T., Gross, R., et al. (2010). Electrical stimulation of the anterior nucleus of thalamus for treatment of refractory epilepsy. Epilepsia 51, 899-908. doi: 10.1111/j.15281167.2010.02536.x

Fisher, R. S. (2011). Neurostimulation for epilepsy: do we know the best stimulation parameters? Epilepsy. Curr. 11, 203-204. doi: 10.5698/1535-7511-11.6.203

Freeman, D. (2010). Electric stimulation with sinusoids and white noise for neural prostheses. Front. Neurosci. 4:28. doi: 10.3389/neuro.20.001.2010

Freeman, D. K., Eddington, D. K., Rizzo, J. F., and Fried, S. I. (2010). Selective activation of neuronal targets with sinusoidal electric stimulation. J. Neurophysiol. 104, 2778-2791. doi: 10.1152/jn.00551.2010

Fröhlich, F., and McCormick, D. A. (2010). Endogenous electric fields may guide neocortical network activity. Neuron 67, 129-143. doi: 10.1016/j.neuron.2010.06.005

Gall, C., Antal, A., and Sabel, B. A. (2013). Non-invasive electrical brain stimulation induces vision restoration in patients with visual pathway damage. Graefes Arch. Clin. Exp. Ophthalmol. 251, 1041-1043. doi: 10.1007/s00417-0122084-7

Ghezzi, D. (2015). Retinal prostheses: progress toward the next generation implants. Front. Neurosci. 9:290. doi: 10.3389/fnins.2015.00290

Gironell, A., Martinez-Horta, S., Aguilar, S., Torres, V., Pagonabarraga, J., PascualSedano, B., et al. (2014). Transcranial direct current stimulation of the cerebellum in essential tremor: a controlled study. Brain Stimul. 7, 491-492. doi: 10.1016/j.brs.2014.02.001

Grassi, G., Godini, L., Grippo, A., Piccagliani, D., and Pallanti, S. (2015). Enhancing cognitive-behavioral therapy with repetitive transcranial magnetic stimulation in refractory obsessive-compulsive-disorder: a case report. Brain Stimul. 8, 160-161. doi: 10.1016/j.brs.2014.10.007

Green, A. L., and Aziz, T. Z. (2014). Steering technology for deep brain stimulation. Brain 137(Pt 7), 1854-1856. doi: 10.1093/brain/awu126

Grover, P. J., Pereira, E. A., Green, A. L., Brittain, J.-S., Owen, S. L., Schweder, P., et al. (2009). Deep brain stimulation for cluster headache. J. Clin. Neurosci. 16, 861-866. doi: 10.1016/j.jocn.2008.10.012

Guillamon, A., McLaughlin, D. W., and Rinzel, J. (2006). Estimation of synaptic conductances. J. Physiol. 100, 31-42. doi: 10.1016/j.jphysparis.2006.09.010

Henn, F. A. (2012). Circuits, cells, and synapses: toward a new target for deep brain stimulation in depression. Neuropsychopharmacology 37, 307-308. doi: 10.1038/npp.2011.193

Herrmann, C. S., Rach, S., Neuling, T., and Struber, D. (2013). Transcranial alternating current stimulation: a review of the underlying mechanisms and modulation of cognitive processes. Front. Hum. Neurosci. 7:279. doi: 10.3389/fnhum.2013.00279

Herz, A. V., Gollisch, T., Machens, C. K., and Jaeger, D. (2006). Modeling singleneuron dynamics and computations: a balance of detail and abstraction. Science 314, 80-85. doi: 10.1126/science. 1127240

Hodaj, H., Alibeu, J. P., Payen, J. F., and Lefaucheur, J. P. (2015). Treatment of chronic facial pain including cluster headache by repetitive transcranial magnetic stimulation of the motor cortex with maintenance sessions: a naturalistic study. Brain Stimul. 8, 801-807. doi: 10.1016/j.brs.2015.01.416

Hodgkin, A. L., and Huxley, A. F. (1952). A quantitative description of membrane current and its application to conduction and excitation in nerve. J. Physiol. 117, 500-544. doi: 10.1113/jphysiol.1952.sp004764

Islam, L., Franzini, A., Messina, G., Scarone, S., and Gambini, O. (2015). Deep brain stimulation of the nucleus accumbens and bed nucleus of stria terminalis for obsessive-compulsive disorder: a case series. World Neurosurg. 83, 657-663. doi: 10.1016/j.wneu.2014.12.024
Izhikevich, E. (2003). Simple model of spiking neurons. IEEE Trans. Neural Netw. 14, 1569-1572. doi: 10.1109/TNN.2003.820440

Jiménez-Ponce, F., Velasco-Campos, F., Castro-Farfán, G., Nicolini, H., Velasco, A. L., Salín-Pascual, R., et al. (2009). Preliminary study in patients with obsessive-compulsive disorder treated with electrical stimulation in the inferior thalamic peduncle. Neurosurgery 65, ons203-ons209. doi: 10.1227/01.neu.0000345938.39199.90

Jorge, R. E., and Robinson, R. G. (2011). Treatment of late-life depression: a role of non-invasive brain stimulation techniques. Int. Rev. Psychiatry 23, 437-444. doi: 10.3109/09540261.2011.633501

Joucla, S., Branchereau, P., Cattaert, D., and Yvert, B. (2012). Extracellular neural microstimulation may activate much larger regions than expected by simulations: a combined experimental and modeling study. PLoS ONE 7:e41324. doi: 10.1371/journal.pone.0041324

Kanai, R., Chaieb, L., Antal, A., Walsh, V., and Paulus, W. (2008). Frequencydependent electrical stimulation of the visual cortex. Curr. Biol. 18, 1839-1843. doi: $10.1016 /$ j.cub.2008.10.027

Kohl, S., Schonherr, D. M., Luigjes, J., Denys, D., Mueller, U. J., Lenartz, D., et al. (2014). Deep brain stimulation for treatment-refractory obsessive compulsive disorder: a systematic review. BMC Psychiatry 14:214. doi: 10.1186/s12888-0140214-y

Krack, P., Fraix, V., Mendes, A., Benabid, A.-L., and Pollak, P. (2002). Postoperative management of subthalamic nucleus stimulation for parkinson's disease. Move. Disord. 17, S188-S197. doi: 10.1002/mds.10163

Krause, B., Marquez-Ruiz, J., and Cohen Kadosh, R. (2013). The effect of transcranial direct current stimulation: a role for cortical excitation/inhibition balance? Front. Hum. Neurosci. 7:602. doi: 10.3389/fnhum.2013. 00602

Lettieri, C., Rinaldo, S., Devigili, G., Pisa, F., Mucchiut, M., Belgrado, E., et al. (2015). Clinical outcome of deep brain stimulation for dystonia: constantcurrent or constant-voltage stimulation? a non-randomized study. Eur. J. Neurol. 22, 919-926. doi: 10.1111/ene.12515

Lewis, P. M., Ackland, H. M., Lowery, A. J., and Rosenfeld, J. V. (2015). Restoration of vision in blind individuals using bionic devices: a review with a focus on cortical visual prostheses. Brain Res. 1595, 51-73. doi: 10.1016/j.brainres.2014.11.020

Liew, S. L., Santarnecchi, E., Buch, E. R., and Cohen, L. G. (2014). Non-invasive brain stimulation in neurorehabilitation: local and distant effects for motor recovery. Front. Hum. Neurosci. 8:378. doi: 10.3389/fnhum.2014.00378

Liu, B. H., Wu, G. K., Arbuckle, R., Tao, H. W., and Zhang, L. I. (2007). Defining cortical frequency tuning with recurrent excitatory circuitry. Nat. Neurosci. 10, 1594-1600. doi: 10.1038/nn2012

Loddenkemper, T., Pan, A., Neme, S., Baker, K. B., Rezai, A. R., Dinner, D. S., et al. (2001). Deep brain stimulation in epilepsy. J. Clin. Neurophysiol. 18, 514-532. doi: 10.1097/00004691-200111000-00002

Lozano, A. M. (2000). Vim thalamic stimulation for tremor. Arch. Med. Res. 31, 266-269. doi: 10.1016/S0188-4409(00)00081-3

Lozano, A. M., and Lipsman, N. (2013). Probing and regulating dysfunctional circuits using deep brain stimulation. Neuron 77, 406-424. doi: 10.1016/j.neuron.2013.01.020

Lu, H., Chestek, C. A., Shaw, K. M., and Chiel, H. J. (2008). Selective extracellular stimulation of individual neurons in ganglia. J. Neural Eng. 5, 287-309. doi: 10.1088/1741-2560/5/3/003

Mainen, Z. F., Joerges, J., Huguenard, J. R., and Sejnowski, T. J. (1995). A model of spike initiation in neocortical pyramidal neurons. Neuron 15, 1427-1439. doi: 10.1016/0896-6273(95)90020-9

Matharu, M. S., and Zrinzo, L. (2011). Deep brain stimulation in cluster headache. Exp. Rev. Neurother. 11, 473-475. doi: 10.1586/ern.11.35

McConnell, G. C., So, R. Q., Hilliard, J. D., Lopomo, P., and Grill, W. M. (2012). Effective deep brain stimulation suppresses low-frequency network oscillations in the basal ganglia by regularizing neural firing patterns. J. Neurosci. 32, 15657-15668. doi: 10.1523/jneurosci.2824-12.2012

McIntyre, C. C., and Grill, W. M. (1999). Excitation of central nervous system neurons by nonuniform electric fields. Biophys. J. 76, 878-888. doi: 10.1016/S0006-3495(99)77251-6

McIntyre, C. C., and Grill, W. M. (2000). Selective microstimulation of central nervous system neurons. Ann. Biomed. Eng. 28, 219-233. doi: 10.1114/1.262 
McIntyre, C. C., and Grill, W. M. (2002). Extracellular stimulation of central neurons: influence of stimulus waveform and frequency on neuronal output. J. Neurophysiol. 88, 1592-1604. Available online at: http://jn.physiology.org/ content/88/4/1592.long

Miller, J. P., and Selman, W. R. (2009). Deep brain stimulation for depression. J. Neurosurg. 111, 1207-1208. doi: 10.3171/2008.1.JNS081353

Miocinovic, S., Somayajula, S., Chitnis, S., and Vitek, J. L. (2013). History, applications, and mechanisms of deep brain stimulation. JAMA Neurol. 70, 163-171. doi: 10.1001/2013.jamaneurol.45

Moliadze, V., Atalay, D., Antal, A., and Paulus, W. (2012). Close to threshold transcranial electrical stimulation preferentially activates inhibitory networks before switching to excitation with higher intensities. Brain Stimul. 5, 505-511. doi: 10.1016/j.brs.2011.11.004

Nelson, T. S., 1. Suhr, C., Freestone, D. R., Lai, A., Halliday, A. J., Mclean, K. J., et al. (2011). Closed-loop seizure control with very high frequency electrical stimulation at seizure onset in the gaers model of absence epilepsy. Int. J. Neural Syst. 21, 163-173. doi: 10.1142/S0129065711002717

Nowak, L. G., and Bullier, J. (1998). Axons, but not cell bodies, are activated by electrical stimulation in cortical gray matter. ii. evidence from selective inactivation of cell bodies and axon initial segments. Exp. Brain Res. 118, 489-500. doi: 10.1007/s002210050305

Nuttin, B. J., GabriAls, L. A., Cosyns, P. R., Meyerson, B. A., Andréewitch, S., Sunaert, S. G., et al. (2008). Long-term electrical capsular stimulation in patients with obsessive-compulsive disorder. Neurosurgery 62(Suppl. 3), SHC966-SHC977. doi: 10.1227/01.neu.0000333764.20575.d6

Obeso, I., Wilkinson, L., Rodrguez-Oroz, M.-C., Obeso, J., and Jahanshahi, M. (2013). Bilateral stimulation of the subthalamic nucleus has differential effects on reactive and proactive inhibition and conflict-induced slowing in parkinsonas disease. Exp. Brain Res. 226, 451-462. doi: 10.1007/s00221-0133457-9

Orosz, I., McCormick, D., Zamponi, N., Varadkar, S., Feucht, M., Parain, D., et al. (2014). Vagus nerve stimulation for drug-resistant epilepsy: a european longterm study up to 24 months in 347 children. Epilepsia 55, 1576-1584. doi: 10.1111/epi.12762

Paulus, W. (2014). Transcranial brain stimulation: potential and limitations. $e$ Neuroforum 5, 29-36. doi: 10.1007/s13295-014-0056-6

Piacentino, M., D'Andrea, G., Perini, F., and Volpin, L. (2014). Drugresistant cluster headache: long-term evaluation of pain control by posterior hypothalamic deep-brain stimulation. World Neurosurg. 81:442e11-5. doi: 10.1016/j.wneu.2013.01.130

Press, W. H., Teukolsky, S. A., Vetterling, W. T., and Flannery, B. P. (2007). Numerical Recipes The Art of Scientific Computing. New York, NY: Cambridge University Press.

Radman, T., Ramos, R. L., Brumberg, J. C., and Bikson, M. (2009). Role of cortical cell type and morphology in subthreshold and suprathreshold uniform electric field stimulation in vitro. Brain Stimul. 2, 215-228, 228e1-3. doi: 10.1016/j.brs.2009.03.007

Reato, D., Rahman, A., Bikson, M., and Parra, L. C. (2013). Effects of weak transcranial alternating current stimulation on brain activity-a review of known mechanisms from animal studies. Front. Hum. Neurosci. 7:687. doi: 10.3389/fnhum.2013.00687

Rizvi, S. J., Donovan, M., Giacobbe, P., Placenza, F., Rotzinger, S., and Kennedy, S. H. (2011). Neurostimulation therapies for treatment resistant depression: a focus on vagus nerve stimulation and deep brain stimulation. Int. Rev. Psychiatry 23, 424-436. doi: 10.3109/09540261.2011.630993

Rizzo, J. F., Wyatt, J., Loewenstein, J., Kelly, S., and Shire, D. (2003). Perceptual efficacy of electrical stimulation of human retina with a microelectrode array during short-term surgical trials. Invest. Ophthalmol. Vis. Sci. 44, 5362. doi: 10.1167/iovs.02-0817

Roth, B. J., and Basser, P. J. (1990). A model of the stimulation of a nerve fiber by electromagnetic induction. IEEE Trans. Biomed. Eng. 37, 588-597. doi: $10.1109 / 10.55662$

Rotstein, H. G., and Nadim, F. (2014). Frequency preference in two-dimensional neural models: a linear analysis of the interaction between resonant and amplifying currents. J. Comput. Neurosci. 37, 9-28. doi: 10.1007/s10827-0130483-3

Salanova, V., Witt, T., Worth, R., Henry, T. R., Gross, R. E., Nazzaro, J. M., et al. (2015). Long-term efficacy and safety of thalamic stimulation for drug-resistant partial epilepsy. Neurol 84, 1017-1025. doi: 10.1212/WNL.0000000000001334

Shin, Y.-I., Foerster, A., and Nitsche, M. A. (2015). Transcranial direct current stimulation (tdcs) application in neuropsychology. Neuropsychologia 69, 154175. doi: 10.1016/j.neuropsychologia.2015.02.002

Sillay, K. A., Sani, S., and Starr, P. A. (2010). Deep brain stimulation for medically intractable cluster headache. Neurobiol. Dis. 38, 361-368. doi: 10.1016/j.nbd.2009.05.020

Sun, X. J., Lei, J. Z., Perc, M., Lu, Q. S., and Lv, S. J. (2011). Effects of channel noise on firing coherence of small-world hodgkin-huxley neuronal networks. Eur. Phys. J. B 79, 61-66. doi: 10.1140/epjb/e2010-10031-3

Traub, R. D., Wong, R. K., Miles, R., and Michelson, H. (1991). A model of a ca3 hippocampal pyramidal neuron incorporating voltage-clamp data on intrinsic conductances. J. Neurophysiol. 66, 635-650.

Vassanelli, S. (2014). Multielectrode and Multitransistor Arrays for In Vivo Recording New York, NY: Springer.

Vassanelli, S., Mahmud, M., Girardi, S., and Maschietto, M. (2012). On the way to large-scale and high-resolution brain-chip interfacing. Cogn. Comput. 4, 71-81. doi: 10.1007/s12559-011-9121-4

Volkmann, J., and Benecke, R. (2002). Deep brain stimulation for dystonia: patient selection and evaluation. Move. Disord. 17, S112-S115. doi: 10.1002/mds.10151

Wang, X. J., and Buzsáki, G. (1996). Gamma oscillation by synaptic inhibition in a hippocampal interneuronal network model. J. Neurosci. 16, 6402-6413.

Watts, D. J., and Strogatz, S. H. (1998). Collective dynamics of 'small-world' networks. Nature 393, 440-442. doi: 10.1038/30918

Zaehle, T., Rach, S., and Herrmann, C. S. (2010). Transcranial alternating current stimulation enhances individual alpha activity in human EEG. PLoS ONE 5:e13766. doi: 10.1371/journal.pone.0013766

Conflict of Interest Statement: The authors declare that the research was conducted in the absence of any commercial or financial relationships that could be construed as a potential conflict of interest.

Copyright (c) 2016 Mahmud and Vassanelli. This is an open-access article distributed under the terms of the Creative Commons Attribution License (CC BY). The use, distribution or reproduction in other forums is permitted, provided the original author(s) or licensor are credited and that the original publication in this journal is cited, in accordance with accepted academic practice. No use, distribution or reproduction is permitted which does not comply with these terms. 